\title{
Misclassification of hypertrophic cardiomyopathy: validation of diagnostic codes
}

\author{
Peter Magnusson ${ }^{1,2}$ \\ Andreas Palm ${ }^{2,3}$ \\ Eva Branden ${ }^{2,4}$ \\ Stellan Mörner ${ }^{5}$ \\ 'Cardiology Research Unit, \\ Department of Medicine, Karolinska \\ Institutet, Stockholm, ${ }^{2}$ Centre for \\ Research and Development, Uppsala \\ University, Region Gävleborg, Gävle, \\ ${ }^{3}$ Department of Medical Sciences, \\ Respiratory, Allergy and Sleep \\ Research, Uppsala University, Uppsala, \\ ${ }^{4}$ Department of Medicine, Karolinska \\ Institutet, Stockholm, ${ }^{5}$ Heart Center \\ and Department of Public Health and \\ Clinical Medicine, Umeå University, \\ Umeå, Sweden
}

This article was published in the following Dove Press journal:

Clinical Epidemiology

9 August 2017

Number of times this article has been viewed

Purpose: To validate diagnostic codes for hypertrophic cardiomyopathy (HCM), analyze misclassfications, and estimate the prevalence of HCM in an unselected Swedish regional cohort.

Patients and methods: Using the hospitals' electronic medical records (used for the Swedish National Patient Register), we identified 136 patients from 2006 to 2016 with the HCM-related codes 142.1 and 142.2 (International Classification of Diseases).

Results: Of a total of 129 residents in the catchment area, 88 patients were correctly classified as HCM (positive predictive value $68.2 \%$ ) and 41 patients $(31.8 \%$ ) were misclassified as HCM. Among the $88 \mathrm{HCM}$ patients (52.2\% males), 74 were alive and 14 were dead (15.9\%). This yields an HCM prevalence of $74 / 183,337$, that is, 4.0 diagnosed cases per 10,000 in the adult population aged $\geq 18$ years. The underlying diagnoses of misclassified cases were mainly hypertension (31.7\%) and aortic stenosis (22.0\%). Other types of cardiomyopathies accounted for several cases of misclassification: dilated (nonischemic or ischemic), left ventricular noncompaction, and Takotsubo. Miscellaneous diagnoses were amyloidosis, pulmonary stenosis combined with ventricular septal defect, aortic insufficiency, athelete's heart, and atrioventricular conduction abnormality. The mean age was not significantly different between HCM and misclassified patients $(65.8 \pm 15.8$ vs $70.1 \pm 13.4$ years; $P=0.177)$. There were $47.8 \%$ females among HCM and $60.8 \%$ females among misclassified $(P=0.118)$.

Conclusion: One-third of patients diagnosed as HCM are misclassified, so registry data should be interpreted with caution. A correct diagnosis is important for decision-making and implementation of optimal HCM care; efforts should be made to increase awareness of HCM and diagnostic competence throughout the health care system.

Keywords: diagnostic error, diagnosis, epidemiology, hypertrophic cardiomyopathy, International Classification of Diseases, register

\section{Introduction}

The diagnosis of hypertrophic cardiomyopathy (HCM) is based on cardiac imaging, genetics, and exclusion of phenocopies or abnormal circulation pathophysiology as an explanation for cardiac hypertrophy. ${ }^{1,2}$ Echocardiograhpy is a cornerstone among diagnostic tools, even though cardiac magnetic resonance (CMR) imaging can be useful, ie, when visualization of the whole chambers is difficult (eg, apical hypertrophy) and to rule out secondary causes. ${ }^{1,2}$ According to the European Society of Cardiology, the diagnosis of HCM requires the myocardial thickness of at least $15 \mathrm{~mm}$ (or $13 \mathrm{~mm}$ if there exists a definite diagnosis in a parent, sibling, or child), which cannot be attributed solely to increased loading conditions. ${ }^{1}$ The loading conditions resulting in hypertrophy may be an adaptation to increased volume/pressure conditions caused by hypertension and/or
Correspondence: Peter Magnusson Cardiology Research Unit, Department of Medicine, Karolinska Institutet, Karolinska University Hospital, Solna, SE-17I 76 Stockholm, Sweden $\mathrm{Tel}+46705089407$

$\mathrm{Fax}+4626154255$ Email peter.magnusson@regiongavleborg. se 
aortic stenosis. Hypertension affects one-fourth of the adult population, ${ }^{3,4}$ aortic stenosis affects $\sim 2-7 \%$ of the elderly, ${ }^{5}$ and both may coexist with HCM. Thus, careful clinical judgment is required to determine if HCM solely explains the hypertrophy. ${ }^{1,2}$

The prevalence of HCM is usually stated as 1:500 (0.2\%), which has been consistently reported in several population studies. ${ }^{6-10}$ In a US cohort (aged 23-35 years), 7 out of 4,111 $(0.17 \%)$ unrelated persons showed signs of hypertrophy on echocardiography but only 1 had cardiac symptoms. ${ }^{6}$ This has been confirmed in later studies of cohorts (mean age 47-60 years) in other US communities, China, and Japan, which report the HCM prevalence of $0.16-0.23 \% .^{7-10}$ Despite advances in health care since Teare's report on HCM $>50$ years ago, accurate HCM diagnosis remains challenging and delayed diagnosis is frequently encountered. ${ }^{11}$

Recently, a database search of 169 million Americans using the International Classification of Diseases, Ninth Revision (ICD-9) for HCM-related diagnosis yielded the prevalence of $1: 3,195$. This study had two important limitations. First, it did not validate HCM diagnoses, so the prevalence may not be correctly reported. Second, this database search excluded the somewhat large subset of patients without health care insurance, suggesting that some patients are never diagnosed. ${ }^{12}$

Patient registries are important sources of information for research and clinical decision making, but the quality of the data depends on the integrity of the diagnostic codes. The Swedish National Patient Register covers $>99 \%$ of all visits in cardiology units nationwide, but even though the quality is generally high, HCM has not been validated specifically. ${ }^{13}$

The aims of this study were to validate diagnostic codes for HCM, analyze misclassifications, and estimate the prevalence of HCM in a Swedish regional cohort.

\section{Methods}

\section{Setting}

The region of Gävleborg is situated in the geographical middle part of Sweden and has 281,815 inhabitants of whom $80.7 \%$ are $>18$ years of age $(227,304)$; the catchment area of the hospitals Gävle Sjukhus and Hudiksvall Sjukhus in Region Gävleborg has 183,337 persons >18 years of age. ${ }^{14}$ The main referral university hospital is Uppsala Akademiska Sjukhus, but other tertiary centers are occasionally involved in the cases of highly specialized management of HCM.

\section{Data validation source}

We searched in the Cyklop ${ }^{\mathrm{TM}}$ system for the HCM-related diagnostic codes I42.1 (obstructive HCM) and I42.2 (other HCM) from International Classification of Diseases, Tenth Revision (ICD-10) from 2006 until October 2016. The hos- pital's electronic medical records system Cyklop provides complete coverage of inpatient and outpatient visits, and data are entered into the national Swedish National Patient Register. ${ }^{13}$ Thus, the records in Cyklop are identical to data from the Swedish National Patient Register. The Swedish population Census Bureau Register is connected to the medical record system Melior ${ }^{\mathrm{TM}}$ and provides a daily update on case fatalities in order to get dates of death. Validation of diagnostic codes using the medical records was performed by a cardiologist with knowledge in the field (PM) and consultation of another expert (SM) when appropriate. The validation was based on guideline definition of HCM. ${ }^{1}$ The validation work was part of a study on HCM and the current study was approved by The Regional Ethical Committee in Uppsala (protocol number 2016/280), which was conducted in compliance with the Declaration of Helsinki. The committee did not require that written informed consent be obtained from the patients as all data was de-identified.

\section{Statistics}

Data were described as frequencies and percentages, and continuous variables were expressed as a mean value with a standard deviation (SD). A Student's $t$-test was used for the comparison of continuous variables, and chi-squared test was used for categorical variables. A two-sided $P$-value of $<0.05$ was considered statistically significant. The positive predictive value refers to the probability that individuals with a diagnosis of HCM truly have the condition HCM and was calculated as the number of "true positives" divided by the sum of "true positives and false positives". The file in Excel 2010 (Microsoft Corporation, Redmond, WA, USA) was transferred into SPSS Version 22 (IBM Corporation, Armonk, NY, USA).

\section{Results}

A total of 136 patients were diagnosed (principal or secondary diagnosis) at least once with HCM (I42.1 and/or I42.2). Seven of these patients were not permanent residents but only temporarily in the region; one of them was misclassified as HCM but was, in fact, situs inversus. Of the remaining 129 patients, 88 were correctly classified as HCM (positive predictive value $68.2 \%$ ), while 41 patients $(31.8 \%)$ were misclassified as HCM. Among the $88 \mathrm{HCM}$ patients, 74 were alive and 14 were dead (15.9\%) at the time of our survey. This yields an HCM prevalence of 74/183,337, that is, 4.0 cases per 10,000 in the adult population aged $\geq 18$ years.

\section{HCM patients}

The characteristics of HCM patients are summarized in Table 1 . Slightly more than half of the cohort was male 
$(\mathrm{n}=46 ; 52.2 \%)$. The mean age was $65.8 \pm 15.7$ years among the 74 living HCM patients. The mean age was different between males and females (60.3 vs 73.2 years; $P<0.001)$. Concomitant hypertension that could not solely explain the hypertrophy that was diagnosed in $34 \%(n=30)$ of patients and these patients are discussed in more detail in Table S1. The localization of the maximal wall thickness was predominantly the left ventricular septum $(n=81 ; 92 \%)$ with the others atypically localized to the apex, posterior, or lateral wall or showing concentric distribution. Echocardiogram was the mode of diagnosis in all cases, although CMR was an adjunctive diagnostic tool in a few cases. Genetic analysis confirmed a disease-causing mutation in a fourth of the patients.

One patient had a heart transplant due to end-stage HCM, but in the vast majority $(86.2 \%, 75 / 87)$ of the remaining patients, beta-blockade was the pharmacological treatment. In one patient, beta-blockade was combined with a calcium channel antagonist and five patients were administered isoptin monotherapy. The choice and dosage of beta-blockers varied: metoprolol $(n=38 ; 43.7 \%)$, bisoprolol $(n=29 ; 33.3 \%)$, carvedilol $(n=4 ; 4.6 \%)$, atenolol $(n=3 ; 3.4 \%)$, and propranolol $(\mathrm{n}=1 ; 1.1 \%)$.

The causes of deaths among HCM patients were progression to end-stage heart failure with depressed ejection fraction $(n=7)$, sudden cardiac death due to ventricular arrhythmia $(n=2)$ and cerebral infarction $(n=1)$, a combination of chronic obstructive pulmonary disease and the early phase of

Table I Characteristics of 88 patients with validated HCM diagnosis

\begin{tabular}{|c|c|}
\hline Variable & HCM patients \\
\hline Age, mean (SD) ${ }^{a}$ & $65.8(15.7)$ \\
\hline Male sex, n (\%) & $46(52.2)$ \\
\hline Diabetes mellitus, $\mathrm{n}(\%)$ & II (I2.5) \\
\hline Hypertension, n (\%) & $30(34.1)$ \\
\hline Atrial fibrillation, $\mathrm{n}(\%)$ & $24(27.3)$ \\
\hline Stroke, n (\%) & $8(9.1)$ \\
\hline COPD, n (\%) & $6(6.8)$ \\
\hline LVEF $<50 \%$, n (\%) & $5(5.7)$ \\
\hline Myectomy, n (\%) & $15(17.0)$ \\
\hline Alcohol septal ablation, $\mathrm{n}(\%)$ & $\mathrm{I}(\mathrm{I} . \mathrm{I})$ \\
\hline Ischemic heart disease ${ }^{\mathrm{b}}, \mathrm{n}(\%)$ & $8(35.8)$ \\
\hline Renal failure, creatinine $>120 \mu \mathrm{mol} / \mathrm{L}, \mathrm{n}(\%)$ & $4(4.5)$ \\
\hline Maximal wall thickness ${ }^{c}(\mathrm{~mm})$, mean $(\mathrm{SD})$ & $19.2(2.9)$ \\
\hline Genopositive, n (\%) & $22(25)$ \\
\hline Heart transplant, $\mathrm{n}(\%)$ & $\mathrm{I}(\mathrm{I} . \mathrm{I})$ \\
\hline ICD, n (\%) & $12(13.6)$ \\
\hline Pacemaker, n (\%) & $10(11.4)$ \\
\hline
\end{tabular}

Notes: aAmong living patients. ${ }^{\mathrm{b}}$ Ischemic heart disease requiring intervention. 'Among patients without previous myectomy/alcohol septal ablation.

Abbreviations: COPD, chronic obstructive pulmonary disease; $\mathrm{HCM}$, hypertrophic cardiomyopathy; ICD, implantable cardioverter defibrillator; LVEF, left ventricular ejection fraction; SD, standard deviation. end-stage heart failure $(n=1)$, perioperative myectomy death $(n=1)$, and noncardiovascular causes $(n=2)$ (renal failure in one patient and abdominal ileus in the other). The mean age at death was 78.8 years and ranged from 43 to 90 years.

\section{Misclassifications}

The most common misclassifications were hypertension $(n=13 ; 31.7 \%)$ and aortic stenosis $(n=9 ; 22 \%)$. Among the 13 cases of hypertension, six patients had a history of maximal hypertrophy of $\geq 15 \mathrm{~mm}$ at any echocardiographic evaluation, while the remaining patients had less pronounced hypertrophy or no hypertrophy at all (Table S2). Other forms of cardiomyopathy without a history of hypertrophy accounted for several cases of misclassification: dilated (nonischemic or ischemic), left ventricular noncompaction, and Takotsubo. Amyloidosis was diagnosed in four cases prior to the publication of new European guidelines, which is in contrast to American guidelines, suggesting that amyloidosis may be a subgroup of HCM. ${ }^{1,2,15}$ Valvular dysfunction, such as pulmonary stenosis, combined with ventricular septal defect and aortic insufficiency was noted among the misclassfications. In addition, athelete's heart was wrongly interpreted as HCM $(n=1)$ and, in another case, a conduction abnormality in the absence of structural disease was misclassified. The case of athelete's heart (the patient was a long-distance runner and weight lifter) was evaluated several times, once with the hypertrophy of $16 \mathrm{~mm}$, but an expert opinion assessed it at 13-14 $\mathrm{mm}$. When the patient decreased training intensity, further regression followed. The complete list of categories of misclassification is shown in Table 2.

The mean age among the living misclassified patients was 70.1 years and ranged from 46 to 96 years. There were

Table 2 Patients with HCM-related diagnostic codes who were misclassified

\begin{tabular}{lll}
\hline Misclassified as HCM & $\begin{array}{l}\text { Misclassified } \\
(\mathbf{n = 4 1 ) ,} \mathbf{n}\end{array}$ & $\begin{array}{l}\text { Cohort } \\
(\mathbf{n}=\mathbf{1 2 9}), \mathbf{n}\end{array}$ \\
$\mathbf{( \% )}$ & $\mathbf{( \% )}$ \\
\hline Hypertension & $13(3 \mathrm{I} .7)$ & 10.1 \\
Aortic stenosis & $9(22.0)$ & 7.0 \\
Amyloidosis & $4(9.8)$ & 3.1 \\
Dilated CM, nonischemic & $4(9.8)$ & 3.1 \\
Dilated CM, ischemic & $2(4.9)$ & 1.6 \\
Left ventricular noncompaction CM & $\mathrm{I}(2.4)$ & 0.8 \\
Takotsubo CM & $\mathrm{I}(2.4)$ & 0.8 \\
Aortic insufficiency & $2(4.9)$ & $\mathrm{I} .6$ \\
Myocardial infarction & $2(4.9)$ & 1.6 \\
Pulmonary stenosis, VSD & $\mathrm{I}(2.4)$ & 0.8 \\
Atrioventricular block, third degree & $\mathrm{I}(2.4)$ & 0.8 \\
Athlete's heart & $\mathrm{I}(2.4)$ & 0.8 \\
\hline
\end{tabular}

Abbreviations: CM, cardiomyopathy; HCM, hypertrophic cardiomyopathy; VSD, ventricular septal defect. 
seven fatal cases $(16.7 \%)$ among the misclassified patients attributed to end-stage heart failure $(n=5)$, stroke $(n=1)$, and sepsis $(n=1)$.

\section{Comparison between HCM and misclassifications}

The mean age among living HCM and misclassified patients did not differ significantly $(65.8 \pm 15.8$ vs $70.1 \pm 13.4$ years; $P=0.177)$. There were $47.8 \%(n=42)$ females among HCM and $60.8 \%(n=25)$ females among misclassified, but the difference was not significant $(P=0.118)$.

\section{Discussion}

\section{HCM remains underdiagnosed}

In this Swedish regional cohort, we confirmed the diagnosis of $\mathrm{HCM}$ in $0.040 \%$, which corresponds to $1: 2,478$. This is in line with US findings of $1: 3,195(0.031 \%)$ using diagnostic codes during year 2013 in a large sample based on insurance statistics. ${ }^{12}$ We share the limitation that the true prevalence of HCM cannot be derived from these databases and sensitivity remains unknown because false classification of true HCM is not accounted for. Nevertheless, the discrepancy from prevalence studies based on outreach programs is striking. ${ }^{6-10}$ HCM likely goes undiagnosed in some patients because they are asymptomatic, have vague symptoms, or do not get included in family screenings.

\section{Diverse diagnoses underlie misclassifications}

Validation of HCM-related diagnoses revealed a large proportion of misclassification. Approximately one-third of the sample had an incorrect HCM diagnosis from a cardiology/ internal medicine facility, which only underlines the diagnostic difficulties in a real-world setting. Notably, there were cases without verified hypertrophy at any cardiac imaging evaluation, which we interpreted as unawareness of the diagnostic cutoff for hypertrophy in HCM. Moreover, slight or borderline hypertrophy in the setting of hypertension was occasionally overlooked, especially when these conditions were persistent and uncontrolled. Guidelines pinpoint that conditions such as severe aortic stenosis and hypertension should be excluded if it explains the hypertrophy, but our findings suggest that this has not been fully implemented in clinical practice. ${ }^{1}$ To address this issue, continuous educational efforts in physician training and close cooperation with highly specialized units are needed. Increased knowledge among cardiologists will improve specificity, but in order to affect sensitivity, ie, to achieve a accurate diagnoses of HCM patients, a more widespread approach is warranted. Increased awareness of HCM throughout the health care system is crucial as symptoms, such as shortness of breath, chest pain, dizziness, and syncope, are common but may relate to any number of causes. An ECG may show signs of hypertrophy and/or T-wave abnormalities in HCM.,16 Echocardiography, although widely available, requires some clinical discernment, and the diagnosis of HCM should be made only after considering other clinical information. , $2,17-20^{-1}$ This also includes cases of hypertrophy regression within a year after controlled hypertension. We noted that only a fourth of HCM patients were genopositive. The finding of a genetic mutation that confirms the disease may help to identify other individuals in the family with HCM and requires cascade screening in collaboration with a molecular genetic unit capable of providing an HCM relevant panel. ${ }^{1,2}$ From our data, we could not determine what percentage of patients underwent genetic testing and why some patients did not.

\section{Reflection on register data}

A Danish effort to study the diagnostic validity of cardiovascular diagnoses included 20 HCM patients; after scrutinizing the medical records, 18 of the diagnoses were deemed correct. ${ }^{21}$ In general, the Swedish National Patient Register data are considered reliable and are used for research and the evaluation of health care quality. ${ }^{13}$ However, the findings from our study underscore that the quality of these data may vary with regard to diagnoses. Registry data should be carefully evaluated, since diagnostic errors might be introduced to cause-of-death registries if invalidated data are taken at face value. Of course, the extent of such errors depends on the nature and purpose of the registry search. Fortunately, in this limited sample, the mean age and sex distribution did not significantly vary between validated HCM patients and misclassifications, which implies less risk of differential bias in epidemiological studies.

\section{Clinical perspectives on HCM}

Few diagnoses have had so many different names as HCM. Over the decades, $>75$ names have been used to describe the entity nowadays known as HCM. ${ }^{22}$ Today, there are two diagnostic codes I42.1 and I42.2 to cover HCM, but in our cohort, they were often used interchangeably. Obstruction as a diagnostic criterion imposes some difficulties in that it is dynamic, may vary with conditions, such as dehydration, and can change with pharmacological regimens. Moreover, observers may vary in how they assess and measure 
obstruction. The same holds true for outflow gradient, which can change over time in the same patient. All of these things make it difficult to diagnose "obstructive" accurately. While obstruction is not necessary for an HCM diagnosis, it may add confusion to the diagnostic workup. In addition, disease progression can vary substantially among patients and end-stage heart failure is a pathway that often results in premature death. ${ }^{23}$

Atrial fibrillation is common in HCM and warrants anticoagulation. ${ }^{24}$ Because correct risk stratification with regard to sudden cardiac death is may improve patient survival, a correct diagnosis of HCM is crucial. Unfortunately, it still seems to be common to overlook cardiac symptoms preceding sudden death in $\mathrm{HCM} .{ }^{25}$ Nevertheless, in general, mortality is low among HCM patients with contemporary management. ${ }^{26}$

Overall, the heterogeneous nature of HCM has to be recognized and each patient followed, according to guidelines, and managed by a multidisciplinary team, which brings expertise in heart failure, cardiac imaging, genetics, electrophysiology, implantable cardioverter defibrillators, and caring sciences in holistic patient-centered care. ${ }^{1,2}$ In addition to specialized HCM teams, we advocate the implementation of educational efforts to a wider range of health care professionals in order to increase general awareness of HCM and raise clinical suspicion for potential HCM cases. Based on the high percentage of misclassifications, it seems necessary to organize and promote multidisciplinary teams with readily available resources to accurately diagnose and optimally treat HCM.

\section{Strength and weaknesses}

This observational study on diagnostic codes with relevance to HCM covers all patients in a regional cohort without selection bias, as all patients are covered by a national insurance system. The high proportion of misclassifications in our study should to be addressed in other geographical areas and health care systems. This study is unable to estimate sensitivity and, thus, cannot address the negative predictive value of HCM. It is likely that in a heterogeneous disease, numerous patients are undiagnosed/misdiagnosed, which implies a high proportion of false negative resulting in lower sensitivity. Due to the small sample size,, statistical hypothesis testing may be subject to type II errors.

\section{Conclusion}

The number of diagnosed HCM is lower than that suggested in population studies. One-third of patients diagnosed with HCM is misclassified as miscellaneous cardiac conditions, mainly hypertension, and aortic stenosis. A correct diagnosis is not only important for individual decision-making on disease management but also important for research purposes. An implementation of improved HCM care should include efforts to increase awareness and competence throughout the health care system.

\section{Acknowledgments}

The authors acknowledge editing by Jo Ann LeQuang from LeQ Medical who reviewed the manuscript for American English use. Britt-Inger Reiterer from Region Gävleborg provided data extraction from the Cyklop ${ }^{\mathrm{TM}}$ register. Region Gävleborg funded this research project.

\section{Author contributions}

PM contributed to the design, statistics, data analysis and interpretation, writing the article, and project management. AP contributed to the design, critical revision, and project management. EB contributed to the design and critical revision. SM contributed to the design, data interpretation, and critical revision. All authors contributed toward data analysis, drafting and critically revising the paper, gave final approval of the version to be published, and agree to be accountable for all aspects of the work.

\section{Disclosure}

The authors report no conflicts of interest in this work.

\section{References}

1. Elliott PM, Anastasakis A, Borger MA, et al. 2014 ESC guidelines on diagnosis and management of hypertrophic cardiomyopathy: the task force for the diagnosis and management of hypertrophic cardiomyopathy of the European Society of Cardiology (ESC). Eur Heart J. 2014;35(39):2733-2779.

2. Sen-Chowdhry S, Jacoby D, Moon J, McKenna WJ. Update on hypertrophic cardiomyopathy and a guide to the guidelines. Nat Rev Cardiol. 2016;13(11):651-675.

3. Kearney PM, Whelton M, Reynolds K, Muntner P, Whelton PK, He Jiang J. Global burden of hypertension: analysis of worldwide data. Lancet. 2005;365(9455):217-223.

4. Nkomo VT, Gardin JM, Skelton TN, Gottdiener JS, Scott CG, EnriquezSarano M. Burden of valvular heart diseases: a population-based study. Lancet. 2006;368(9540):1005-1011.

5. Iung B, Baron G, Butchart EG, et al. A prospective survey of patients with valvular heart disease in Europe: the euro heart survey on valvular heart disease. Eur Heart J. 2003;24(13):1231-1243.

6. Maron BJ, Gardin JM, Flack JM, Gidding SS, Kurosaki TT, Bild DE. Prevalence of hypertrophic cardiomyopathy in a general population of young adults. Echocardiographic analysis of 4111 subjects in the CARDIA study. Coronary artery risk development in (young) adults. Circulation. 1995;92(4):785-789.

7. Zou Y, Song L, Wang Z, et al. Prevalence of idiopathic hypertrophic cardiomyopathy in China: a population-based echocardiographic analysis of 8080 adults. Am J Med. 2004;116(1):14-18.

8. Hada Y, Sakamoto T, Amano K, et al. Prevalence of hypertrophic cardiomyopathy in a population of adult Japanese workers as detected by echocardiographic screening. Am J Cardiol. 1987;59(1):183-184. 
9. Maron BJ, Spirito P, Roman MJ, et al. Prevalence of hypertrophic cardiomyopathy in a population-based sample of American Indians aged 51 to 77 years (the Strong Heart Study). Am J Cardiol. 2004;93(12):1510-1514.

10. Maron BJ, Mathenge R, Casey SA, Poliac LC, Longe TF. Clinical profile of hypertrophic cardiomyopathy identified de novo in rural communities. J Am Coll Cardiol. 1999;33(6):1590-1595.

11. McKenna WJ, Sen-Chowdhry S. From Teare to the present day: a fifty year odyssey in hypertrophic cardiomyopathy, a paradigm for the logic of the discovery process. Rev Esp Cardiol. 2008;61(12):1239-1244.

12. Maron MS, Hellawell JL, Lucove JC, Farzaneh-Far R, Olivotto I. Occurrence of clinically diagnosed hypertrophic cardiomyopathy in the United States. Am J Cardiol. 2016;117(10):1651-1654.

13. Ludvigsson JF, Andersson E, Ekbom A, et al. External review and validation of the Swedish national inpatient register. BMC Public Health. 2011;11:450.

14. Statistikdatabasen. [Statistics Sweden]; 2016. Available from: http:// www.statistikdatabasen.scb.se/pxweb/sv/ssd/START__BE_BE0101_ BE0101A/BefolkningNy/?rxid=67c80f1d-e68b-424b-981d-c843cf 448195. Accessed Dec 28, 2016.

15. Gersh BJ, Maron BJ, Bonow RO, et al; American College of Cardiology Foundation/American Heart Association Task Force on Practice Guidelines; American Association for Thoracic Surgery; American Society of Echocardiography; American Society of Nuclear Cardiology; Heart Failure Society of America; Heart Rhythm Society; Society for Cardiovascular Angiography and Interventions; Society of Thoracic Surgeons. 2011 ACCF/AHA guideline for the diagnosis and treatment of hypertrophic cardiomyopathy: executive summary: a report of the American College of Cardiology Foundation/American Heart Association task force on practice guidelines. Circulation. 2011;124(24):2761-2796.

16. McLeod CJ, Ackerman MJ, Nishimura RA, Tajik AJ, Gersh BJ, Ommen SR. Outcome of patients with hypertrophic cardiomyopathy and a normal electrocardiogram. J Am Coll Cardiol. 2009;54(3):229-233.

17. Smith N, Steeds R, Masani N, et al. A systematic approach to echocardiography in hypertrophic cardiomyopathy: a guideline protocol from the British Society of Echocardiography. Echo Res Pract. 2015;2(1):G1-G7.
18. Rapezzi C, Arbustini E, Caforio AL, et al. Diagnostic work-up in cardiomyopathies: bridging the gap between clinical phenotypes and final diagnosis. A position statement from the ESC working group on myocardial and pericardial diseases. Eur Heart J. 2013;34(19):1448-1458.

19. Losi MA, Nistri S, Galderisi M, et al; Working Group of Echocardiography of the Italian Society of Cardiology. Echocardiography in patients with hypertrophic cardiomyopathy: usefulness of old and new techniques in the diagnosis and pathophysiological assessment. Cardiovasc Ultrasound. 2010;8:7.

20. Klues HG, Schiffers A, Maron BJ. Phenotypic spectrum and patterns of left ventricular hypertrophy in hypertrophic cardiomyopathy: morphologic observations and significance as assessed by two-dimensional echocardiography in 600 patients. J Am Coll Cardiol. 1995;26(7):1699-1708.

21. Sundbøll J, Adelborg K, Munch T, et al. Positive predictive value of cardiovascular diagnoses in the Danish National Patient Registry: a validation study. BMJ Open. 2016;6(11):e012832.

22. Maron BJ, Maron MS. A discussion of contemporary nomenclature, diagnosis, imaging, and management of patients with hypertrophic cardiomyopathy. Am J Cardiol. 2016;118(12):1897-1907.

23. Pasqualucci D, Fornaro A, Castelli G, et al. Clinical spectrum, therapeutic options, and outcome of advanced heart failure in hypertrophic cardiomyopathy. Circ Heart Fail. 2015;8(6):1014-1021.

24. Guttmann OP, Rahman MS, O’Mahony C, Anastasakis A, Elliott PM. Atrial fibrillation and thromboembolism in patients with hypertrophic cardiomyopathy: systematic review. Heart. 2014;100(6):465-472.

25. Lynge TH, Risgaard B, Jabbari R, et al. Cardiac symptoms before sudden cardiac death caused by hypertrophic cardiomyopathy: a nationwide study among the young in Denmark. Europace. 2016;18(12): 1801-1808.

26. Maron BJ, Rowin EJ, Casey SA, et al. Hypertrophic cardiomyopathy in adulthood associated with low cardiovascular mortality with contemporary management strategies. J Am Coll Cardiol. 2015;65(18):1915-1928. 


\section{Supplementary materials}

Table SI Patients with HCM and concomitant hypertension

\begin{tabular}{|c|c|}
\hline $\begin{array}{l}\text { Correct HCM with } \\
\text { hypertension }(n=30)\end{array}$ & Description \\
\hline Female, born 1922, died 2015 & $\begin{array}{l}\text { Septal and midseptal hypertrophy } 17 \mathrm{~mm} \text {, ECG repolarization abnormalities, maximal LVOT gradient } 68 \mathrm{mmHg} \text {, } \\
\text { mild controlled hypertension }\end{array}$ \\
\hline Female, born 1924, died 2013 & $\begin{array}{l}\text { Septal hypertrophy } 18 \mathrm{~mm} \text {, mean gradient } 58 \mathrm{mmHg} \text {, pacemaker due to reduced obstruction, ECG repolarization } \\
\text { abnormalities, mild controlled hypertension }\end{array}$ \\
\hline Female, born 1926, died 2015 & $\begin{array}{l}\text { Septal hypertrophy } 17 \mathrm{~mm}, V_{\max } 2.8 \mathrm{~m} / \mathrm{s} \text {, ECG repolarization abnormalities, mild controlled hypertension with a } \\
\text { short history }\end{array}$ \\
\hline Female, born 1928, died 2016 & Septal and midseptal hypertrophy $20 \mathrm{~mm}, V_{\max } 3.8 \mathrm{~m} / \mathrm{s}$, mild controlled hypertension \\
\hline Male, born I93I, died 2013 & Septal hypertrophy $17 \mathrm{~mm}$, MYBPC positive, mild hypertension \\
\hline Female, born 1931, died 2016 & Septal hypertrophy $20 \mathrm{~mm}, V_{\max } 4.2 \mathrm{~m} / \mathrm{s}$, mild controlled hypertension, heredity for sudden death \\
\hline Female, born 1933, died 2013 & $\begin{array}{l}\text { Septal hypertrophy } 17 \mathrm{~mm}, V_{\max } 2.6 \mathrm{~m} / \mathrm{s} \text {, unexplained syncope, ECG repolarization abnormalities, mild controlled } \\
\text { hypertension }\end{array}$ \\
\hline Female, born 1937, died 2012 & Septal, midseptal hypertrophy $21 \mathrm{~mm}$, ECG repolarization abnormalities, mild controlled hypertension \\
\hline Female, 95 years & Septal hypertrophy $22 \mathrm{~mm}$, ECG repolarization abnormalities, mild controlled hypertension \\
\hline Male, 89 years & $\begin{array}{l}\text { Apical hypertrophy, not reported maximal thickness, ECG repolarization abnormalities, mild controlled } \\
\text { hypertension }\end{array}$ \\
\hline Female, 85 years & Septal-apical hypertrophy $17 \mathrm{~mm}$, grandmother sudden death at 56 years, MYBPC, mild controlled hypertension \\
\hline Female, 83 years & Inferolateral hypertrophy $19 \mathrm{~mm}$, ECG repolarization abnormalities, mild controlled hypertension \\
\hline Female, 81 years & Septal hypertrophy $20 \mathrm{~mm}, 2.3 \mathrm{~m} / \mathrm{s}$, ECG repolarization abnormalities, mild controlled hypertension \\
\hline Female, 78 years & Septal hypertrophy $26 \mathrm{~mm}, 4.1 \mathrm{~m} / \mathrm{s}$, myectomy, ECG repolarization abnormalities, mild controlled hypertension \\
\hline Female, 76 years & Septal hypertrophy $19 \mathrm{~mm}, 3.7 \mathrm{~m} / \mathrm{s}$, ECG repolarization abnormalities, mild controlled hypertension \\
\hline Male, 74 years & Septal-midseptal hypertrophy $24 \mathrm{~mm}, 2.4 \mathrm{~m} / \mathrm{s}$, ECG repolarization abnormalities, mild controlled hypertension \\
\hline Male, 74 years & $\begin{array}{l}\text { Septal hypertrophy } 26 \mathrm{~mm} \text {, myectomy, genopositive, ECG repolarization abnormalities, mild controlled } \\
\text { hypertension }\end{array}$ \\
\hline Female, 74 years & Septal hypertrophy $18 \mathrm{~mm}, 3.1 \mathrm{~m} / \mathrm{s}$, ECG repolarization abnormalities, mild controlled hypertension \\
\hline Female, 74 years & Septal hypertrophy $21 \mathrm{~mm}, 2.2 \mathrm{~m} / \mathrm{s}$, ECG repolarization abnormalities, mild controlled hypertension \\
\hline Female, 73 years & Septal hypertrophy $19 \mathrm{~mm}, 4.4 \mathrm{~m} / \mathrm{s}$, ECG repolarization abnormalities, mild controlled hypertension \\
\hline Female, 73 years & Septal hypertrophy $22 \mathrm{~mm}, 4.8 \mathrm{~m} / \mathrm{s}$, ECG repolarization abnormalities, mild controlled hypertension \\
\hline Male, 71 years & Septal hypertrophy $21 \mathrm{~mm}, 2.9 \mathrm{~m} / \mathrm{s}$, ECG repolarization abnormalities, mild controlled hypertension \\
\hline Male, 71 years & Septal hypertrophy $23 \mathrm{~mm}$, myectomy, $5.6 \mathrm{~m} / \mathrm{s}$, ECG repolarization abnormalities, mild controlled hypertension \\
\hline Female, 7 I years & $\begin{array}{l}\text { Septal hypertrophy } 24 \mathrm{~mm} \text {, myectomy, sudden death of two cousins, ECG repolarization abnormalities, mild } \\
\text { controlled hypertension }\end{array}$ \\
\hline Female, 70 years & Posterior hypertrophy $19 \mathrm{~mm}$, ECG repolarization abnormalities, mild controlled hypertension \\
\hline Female, 66 years & Septal hypertrophy, myectomy, MYH7 positive, ECG repolarization abnormalities, mild controlled hypertension \\
\hline Male, 60 years & Septal hypertrophy $23 \mathrm{~mm}$, ECG repolarization abnormalities, mild controlled hypertension \\
\hline Male, 57 years & Septal hypertrophy $22 \mathrm{~mm}$, ECG repolarization abnormalities, mild controlled hypertension \\
\hline Male, 57 years & $\begin{array}{l}\text { Septal hypertrophy } 20 \mathrm{~mm} \text {, mean gradient } 80 \mathrm{mmHg} \text {, ECG repolarization abnormalities, mild controlled } \\
\text { hypertension }\end{array}$ \\
\hline Male, 54 years & $\begin{array}{l}\text { Septal hypertrophy } 19 \mathrm{~mm} \text {, maximum gradient } 39 \mathrm{mmHg} \text {, unexplained syncope ECG repolarization abnormalities, } \\
\text { mild controlled hypertension }\end{array}$ \\
\hline
\end{tabular}

Abbreviations: ECG, electrocardiogram; HCM, hypertrophic cardiomyopathy; LVOT, left ventricular outflow tract; MYBPC, myosin binding protein C; $V_{\text {max' }}$, velocity maximal. 
Table S2 Patient with hypertension misclassified as HCM

\begin{tabular}{|c|c|}
\hline Misclassified as HCM & Reclassified $(n=13)$ as hypertension \\
\hline Female, 88 years & Septum 14 mm, hypertension for several years \\
\hline Female, born 1932, died 2016 & Severe hypertension for several years but no cardiac imaging ever done \\
\hline Male, 78 years & Concentric hypertrophy $16 \mathrm{~mm}$, uncontrolled hypertension for several years \\
\hline Female, 77 years & $\begin{array}{l}\text { "Minimal hypertrophy" at echocardiography report without specific measurements. Malignant hypertension with } \\
\text { systolic blood pressure }>220 \mathrm{mmHg} \text { at repeated measurements. Never reached controlled hypertension }\end{array}$ \\
\hline Female, 77 years & Septal bullae $14.5 \mathrm{~mm}$, hypertension for at least 16 years \\
\hline Female, 76 years & $\begin{array}{l}\text { Minimal hypertrophy and } 16 \mathrm{~mm} \text { localized basal septal hypertrophy. Hypertension for several years and } \\
\text { regression of hypertrophy }\end{array}$ \\
\hline Male, 76 years & Severe hypertension for several years, partly uncontrolled. No cardiac imaging \\
\hline Female, born 194I, died 2016 & $\begin{array}{l}\text { Septum } 15-18 \mathrm{~mm} \text { at different echocardiography examinations and mild aortic stenosis. Overestimation of } \\
\text { hypertrophy (18 mm) attributed to inexperienced examiner. Later estimated at } 15 \mathrm{~mm} \text {. History of hypertension } \\
\text { for at least } 12 \text { years }\end{array}$ \\
\hline Female, 72 years & $\begin{array}{l}\text { Septum } 15-17 \mathrm{~mm} \text { and concentric hypertrophy. Severe hypertension and repeatedly systolic blood pressure } \\
>170 \mathrm{mmHg} \text { despite medication (probably not fully compliant) }\end{array}$ \\
\hline Male, 72 years & Hypertension. Echocardiography did not show hypertrophy (10 mm) \\
\hline Female, 64 years & $\begin{array}{l}\text { Slight proximal septal hypertrophy, maximum } 15-16 \mathrm{~mm} \text {, on echocardiogram. Uncontrolled hypertension for } \\
\text { several years }\end{array}$ \\
\hline Female, 48 years & $\begin{array}{l}\text { Repeated echocardiograms but septum never }>13 \mathrm{~mm} \text {, no obstruction, no systolic anterior motion. Controlled } \\
\text { hypertension of unknown duration }\end{array}$ \\
\hline Male, 46 years & $\begin{array}{l}\text { Septum I4-15 mm, no obstruction, no systolic anterior motion. Malignant hypertension } 240 \mathrm{mmHg} \text {, } \\
\text { uncontrolled hypertension for several years }\end{array}$ \\
\hline
\end{tabular}

Abbreviation: HCM, hypertrophic cardiomyopathy.

\section{Publish your work in this journal}

Clinical Epidemiology is an international, peer-reviewed, open access, online journal focusing on disease and drug epidemiology, identification of risk factors and screening procedures to develop optimal preventative initiatives and programs. Specific topics include: diagnosis, prognosis, treatment, screening, prevention, risk factor modification,

Submit your manuscript here: https://www.dovepress.com/clinical-epidemiology-journal

\section{Dovepress}

systematic reviews, risk and safety of medical interventions, epidemiology and biostatistical methods, and evaluation of guidelines, translational medicine, health policies and economic evaluations. The manuscript management system is completely online and includes a very quick and fair peer-review system, which is all easy to use. 